\title{
Antibiotic Activity of Actinomycetes Isolated from Young Tectona Grandis (L.) Wood and Pith
}

\author{
Rio Risandiansyah ${ }^{1, *(\mathbb{D})}$, Arif Yahya ${ }^{1}$ \\ 1 Faculty of Medicine, Universitas Islam Malang, Malang, Indonesia \\ * Correspondence: riorisandiansyah @ unisma.ac.id (R.R.);
}

Received: 5.10.2021; Revised: 10.11.2021; Accepted: 14.11.2021; Published: 9.12.2021

\begin{abstract}
Actinomycetes are a source for novel bioactive compounds and justify obtaining new species from various sources. Hardwoods such as Tectona grandis (L.) have not been studied for actinomycete isolation. We aim to isolate endophytic actinomycetes from young Tectona grandis wood and pith and screen for antibiotic activity. Five young wood were cut and surface sterilized using ethanol and hypochlorous acid. The wood and pith of each sample are placed in eight plates of Humic acid-vitamin B (HV), Tap water Yeast extract (TWYE), and Yeast Extract Casein Digest (YECD) medium and incubated at $27^{\circ} \mathrm{C}$ for four weeks. Actinomycetes were isolated from such medium, observed every week, and transferred to an International Streptomyces Project-2 (ISP-2) medium for identification and antibiotic production tested against Staphylococcus aureus, Helicobacter pylori, and Escherichia coli using the Kirby-Bauer method. Seven actinomycetes were isolated from the wood, primarily from YECD and TWYE media, with varying morphological characteristics. One isolate having marooncolored aerial and vegetative mycelium with grey spores showed moderate antibacterial activity against $S$. aureus and $H$. pylori $(13.49 \pm 1.03 \mathrm{~mm}$ and $14.9 \pm 0.7 \mathrm{~mm}$, respectively), while two other actinomycetes showed weak activity against these bacteria. However, none of the actinomycetes show any activity against E. coli. Tectona grandis (L.) is a potential source for novel actinomycetes with an antibiotic activity which warrants further exploration
\end{abstract}

Keywords: actinomycetes isolation; antibacterial activity; drug discovery.

(C) 2021 by the authors. This article is an open-access article distributed under the terms and conditions of the Creative Commons Attribution (CC BY) license (https://creativecommons.org/licenses/by/4.0/).

\section{Introduction}

Novel antibiotics are currently in demand due to the increasing amount of antibiotic resistance. In 2050, it is predicted that death due to antibiotic resistance will reach 10 million people [1,2]. One solution for curbing antibiotic resistance is the discovery of novel antibiotics having unique and novel structures that may have different bacterial targets or modes of action or be used in conjunction with currently available antibiotics to increase their activity $[3,4]$. Therefore, drug discovery studies, particularly for antibiotics, are research being conducted in many research centers across the globe.

A promising source of antibiotics is actinobacteria [5,6], with its largest group consisting of Streptomyces. Streptomyces and other actinomycetes are the sources of most antibiotics currently used today and other types of bioactive compounds, including the antibiotics discovered after the 2000s [4,7]. These compounds usually have complex structures and are not easily synthesized, and have various medical uses and bioactivities [7,8]; thus, the discovery of novel compounds from actinomycetes is a goal of interest in drug discovery [9].

The isolation of actinomycetes from various and unique sources is an essential step to achieving that goal $[4,10]$. Actinomycetes have been isolated from multiple sources, with novel 
species discovered from unlikely sources or niches. Isolation of actinomycetes has been conducted on soil samples from various geographical locations [11-13], medicinal plants [14$16]$, and even from the guts of termites or other insects $[17,18]$. In nature, actinomycetes are soil-dwellers and endophytic bacteria, occupying the roots, leaves, or bark of various plants or trees $[19,20]$. In regards to that, Indonesia is researched to be rich in biodiversity and plant species, although it is said to be in decline [21]. However, isolation of actinomycetes from these sources has seldom been conducted, resulting in a mostly untapped natural source for novel species as well as novel bioactive compounds.

Although many studies have successfully isolated actinomycetes from different old and young trees, whether from the roots, leaves, or barks, the isolation of actinomycetes from hardwood trees has been difficult. Novel actinomycetes have been discovered to also dwell inside the wood, even those already used as wooden walls [22]. However, the problem arises in the pre-treatment of the wood. In most studies, to obtain sufficient actinomycetes, the samples must be surface sterilized and ground into $1-2 \mathrm{~mm}$ fragments in sterile conditions $[19,23]$. While a blender may be used in leaves or roots dried overnight, only an industrialgrade blender would be able to cut hardwoods. This may result in hardwood isolation studies being currently sparser compared to other parts of the tree.

This study aims to isolate actinomycetes from the wood of Tectona grandis (L.), also known as 'Jati', from Dau region, Malang, Indonesia, a hardwood usually used in the manufacture of expensive and durable wooden furniture. To somewhat alleviate the difficulty of wood pre-treatment in isolation, the samples used are branches from one-year-old trees, mostly $3-5 \mathrm{~cm}$ in diameter. After surface sterilization, these would be fragmented using a sterilized carving tool. Due to the relatively softer wood of the younger trees, it would be possible to do it manually. Following this, the actinomycetes would be grown in a production medium and screened for antibacterial activity against Gram-positive and Gram-negative bacteria.

\section{Materials and Methods}

\subsection{General background of research.}

This research is an in vitro laboratory study conducted at Laboratorium Pusat Riset Kedokteran, Universitas Islam Malang, Indonesia, between January to July 2021.

\subsection{Sample of research.}

Young Tectona grandis (L.) trees were obtained from Dau, Malang, and identified based on morphological characteristics of the leaves, whereas the trees fit the description published in the literature. Leaves were ovate-elliptic to ovate approximately $20-30 \mathrm{~cm}$ in length and $10-20 \mathrm{~cm}$ in width and petioles at $2-4 \mathrm{~cm}$ long. The trees used in the samples were $1.5-2 \mathrm{~m}$ tall and $10-15 \mathrm{~cm}$ thick, with grey or grayish brown branches. No flowers or fruits were observed. This study also uses Escherichia coli, Helicobacter pylori, and Staphylococcus aureus to represent Gram-positive and Gram-negative bacteria. E. coli and S. aureus bacteria were Certified Reference Microorganism (CRM) cultures, with a catalog number for E. coli of VT000122-10EA and S. aureus subspecies aureus of VT000322-10EA, while Helicobacter pylori were obtained from the Microbiology Laboratory, Universitas Muhammadiyah Malang, Indonesia. 


\subsection{Surface sterilization of wood samples.}

A single branch was collected from five different trees. Surface sterilization of the obtained branches was done following previous literature with some modifications [23]. The branches were submerged in 99\% ethanol for 60 seconds, transferred in a $3.125 \% \mathrm{NaOCl}$ solution for 6 minutes, in a different batch of $99 \%$ ethanol for 30 seconds, and finally rinsed in distilled water and left overnight to dry. Using a sterilized carving tool and aseptic conditions, the branch was broken open to reveal the wood and piths. The wood was then shaved into thin, $0.5-1 \mathrm{~cm}$ pieces and collected. Using sterile tweezers, the pith was also broken into the same size pieces and collected in a different container. This was repeated for all five branches.

\subsection{Sample inoculation and isolation of actinomycetes.}

Three different isolation media were prepared, following previous literature [23]. Fragments of wood and pith were separately inoculated (at eight to ten fragments per plate) in eight taps of water-yeast extract agar (TWYE, $0.25 \mathrm{~g}$ yeast extract [Oxoid], $0.5 \mathrm{~g} \mathrm{~K}_{2} \mathrm{HPO}_{4}, 18$ $\mathrm{g}$ agar [Himedia], and one liter of tap water), eight yeast extract-casein hyrdosylate agar (YECD, $0.3 \mathrm{~g}$ yeast extract [Oxoid], $0.3 \mathrm{~g}$ glucose anhydrous, $2 \mathrm{~g} \mathrm{~K}_{2} \mathrm{HPO}_{4}, 18 \mathrm{~g}$ agar [Himedia], and one liter of distilled water), and eight humic acid-vitamin $\mathrm{B}$ agar (HV, $1 \mathrm{~g}$ Humic Acid, $0.5 \mathrm{~g} \mathrm{~K}_{2} \mathrm{HPO}_{4}, 1.71 \mathrm{~g} \mathrm{KCl}$, ).05 g MgSO $4.7 \mathrm{H}_{2} \mathrm{O}, 0.01$ g FeSO $4.7 \mathrm{H}_{2} \mathrm{O}, 0.02 \mathrm{~g}$ $\mathrm{CaCO}_{3}, 0.5 \mathrm{mg}$ Vitamine $\mathrm{B}, 18 \mathrm{~g}$ agar, and one liter of distilled water). After inoculation, the media were incubated in a $27^{\circ} \mathrm{C}$ incubator for four weeks, checking every three days. Actinomycete cultures were transferred into an International Streptomyces Project 2 medium (ISP2, $4 \mathrm{~g}$ yeast extract [Oxoid], $10 \mathrm{~g}$ malt extract (Sigma), $4 \mathrm{~g}$ glucose anhydrous, $15 \mathrm{~g}$ agar [Himedia]) for morphological identification. All media was first adjusted for $\mathrm{pH}$ to $7.2 \pm 0.2$ and sterilized using an autoclave at $121^{\circ} \mathrm{C}$ for 15 minutes.

\subsection{Morphological observation and putative identification of obtained cultures.}

Cultures were coded based on the isolation, tree number, plate number, and isolate number. After transferring actinomycetes to an ISP2 medium, as previously described [24], the plates were incubated at $27^{\circ} \mathrm{C}$. After five days, the morphological characteristics were noted. After incubation for ten days, a sample of a well-sporulated culture was obtained and observed under a light microscope at 400x or 1000x magnification to note spore formation.

\subsection{Extraction of active compounds from obtained cultures.}

For antibiotic production, the cultures were streaked in a lawn fashion in ISP2 medium to achieve sufficient biomass. After fourteen days of incubation in ISP2 medium, a small-scale extraction was performed on the plates, following previous literature [25]. The ISP2 medium was cut up (along with the lawn bacteria after sporulation was observed) in $1 \mathrm{~cm}$ cubes. These were then submerged in $20 \mathrm{ml}$ methanol and shaken at $\pm 120 \mathrm{rpm}$ for 24 hours for the extraction process. The cubes and bacteria were filtered out using filter paper. Then, these extracts were then used for antibacterial screening.

\subsection{Antibacterial assay from extracts.}

The antibacterial assay was conducted using a Kirby-Bauer method, following guidelines from the American Society of Microbiology (ASM) [26]. The bacteria used were 
first grown in a nutrient agar medium [Himedia] (NA, $5 \mathrm{~g}$ peptone, $5 \mathrm{~g} \mathrm{NaCl}, 1.5 \mathrm{~g} \mathrm{HM}$ peptone $\mathrm{B}, 1.5 \mathrm{~g}$ yeast extract, $15 \mathrm{~g}$ agar, and 11 distilled water) into separate, identifiable colonies were observed. From each plate, colonies were transferred into a $10 \mathrm{ml} 0.9 \% \mathrm{NaCl}$ solution and were compared to a $0.5 \mathrm{McF}$ arland standard. The colonies were homogenized using a vortex and added until the bacterial solution had an approximate density similar to the McFarland standard. Also, a sample of the already homogenized bacterial solution was checked using a spectrophotometer at a wavelength of $600 \mathrm{~nm}$ to ensure that the optical density was between $0.08-0.1$. Using a steril cotton swab, the suspension was inoculated onto a Mueller-Hinton Agar plate [Himedia] (MHA) in a zig-zag manner, according to the guideline above. The blank antibiotic testing discs were then submerged into the previously obtained extracts and left for 10 minutes. Then, the discs were carefully placed on top of the MHA agar inoculated with bacteria. The plate was then incubated at $37^{\circ} \mathrm{C}$ for $18-24$ hours. A clear zone signified antibacterial activity and was measured using a caliper and reported in millimeters. This assay was replicated three times for each bacterium.

\subsection{Data analysis.}

Statistical data on the zone of inhibition was analyzed using multiple T-test to determine significant differences. Each antibacterial assay was conducted in triplicates.

\section{Results and Discussion}

\subsection{Morphological characteristics of isolated actinomycetes from different media.}

Isolation efforts resulted in a low number of actinomycetes due to an overabundance of fungal cultures, both from the wood and the pith, in all media tested. The pith of the wood seldom resulted in any actinomycetes but was a novel source of possibly novel fungal microorganisms. Furthermore, actinomycetes cultures were isolated in the $1^{\text {st }}$ and $2^{\text {nd }}$ week, and no new cultures emerged after the $3^{\text {rd }}$ or $4^{\text {th }}$ week of examination. Overall, seven actinomycetes morphologically different cultures are reported in this study. The morphological and microscopic characteristics of actinomycete cultures are summarized in Table 1 and can be evaluated in Figure 1.

Most actinomycetes isolated from this study originated from the wood, in which only one, T4P11, was found from pith samples. Based on its mycelium characteristics, seven isolates were isolated and tested for actinomycetes, although some found to have had similar mycelium characteristics were collated into one sample. However, although the coloring of the aerial mycelium was the same between one culture and the other, the coarseness of the cultures and overall surface characteristics was taken into account when determining different species. Most show good sporulation after 10 days of incubation, except Y4K23, which had poor sporulation in ISP2 even after 14 days. It is suspected that most of the actinomycetes discovered were Streptomyces based on the observation of its mycelium or spores.

In this study, several issues were met that may have lowered the number of cultures obtained. While HVA medium used in this study is known to be selective for actinomycetes $[19,27]$, no actinomycetes were successfully cultivated from this medium. On the contrary, while TWYE and YECD medium used in this study have also previously been successful in isolating actinomycetes [23,28], however, aside from the actinomycetes obtained from these plates, many plates were overgrown with different and various types of fungi, in which its inclusion was not within the scope of this paper. 
(a)

\section{Aerial mycelium}

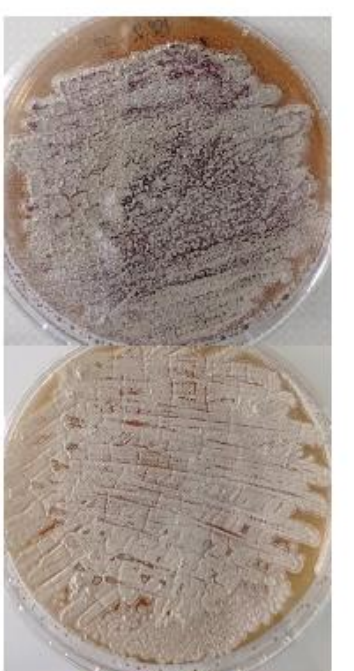

(c)

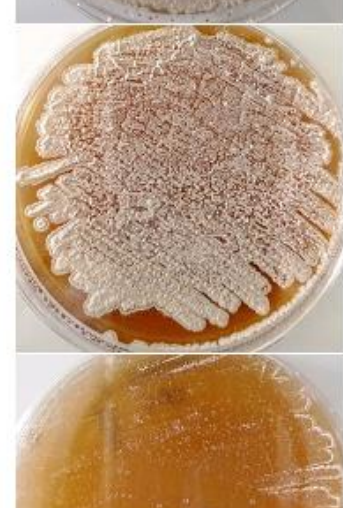

(d)

(e)

(f)
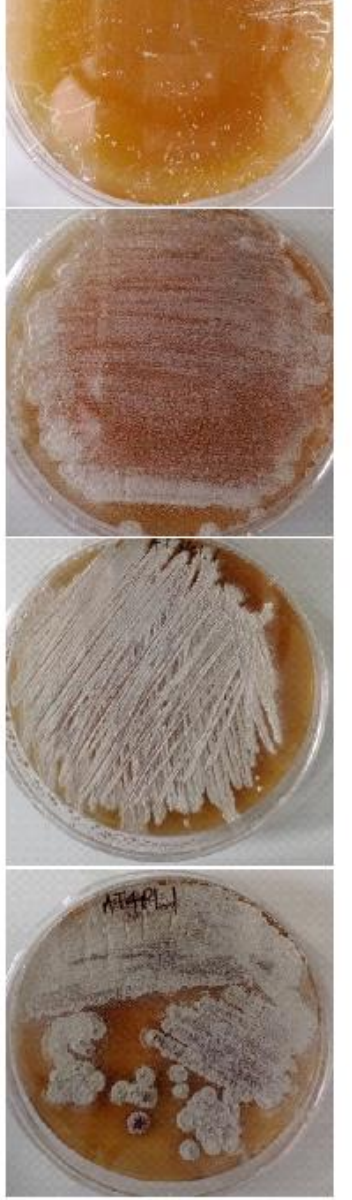

Vegetative mycelium
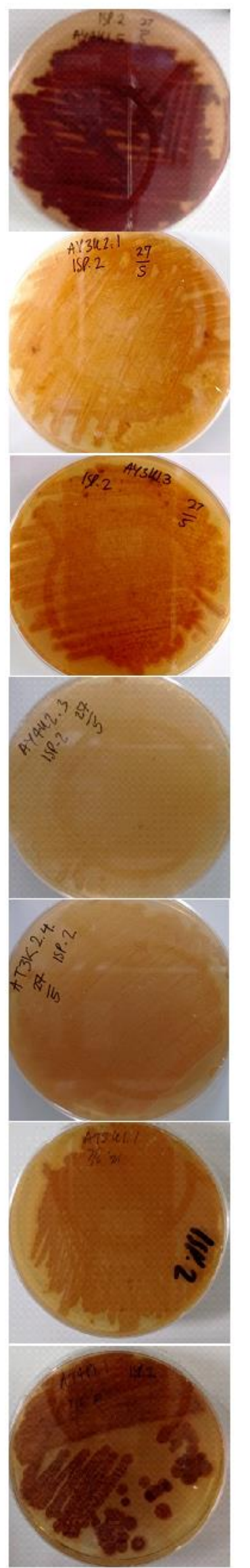

Microscopic observation of spores
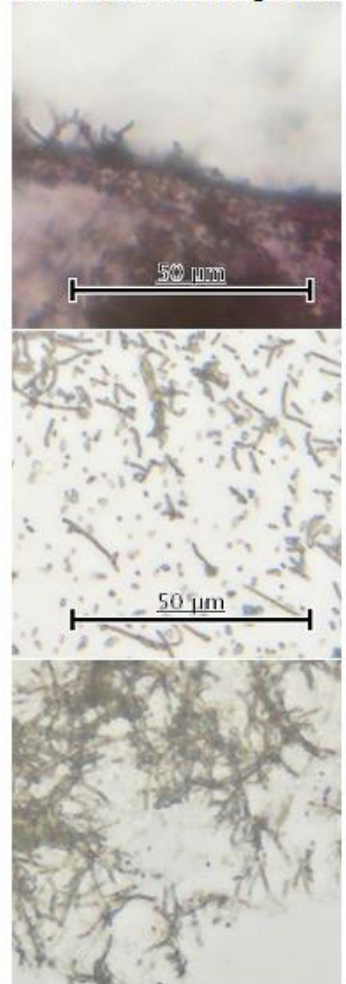

No spores were observed

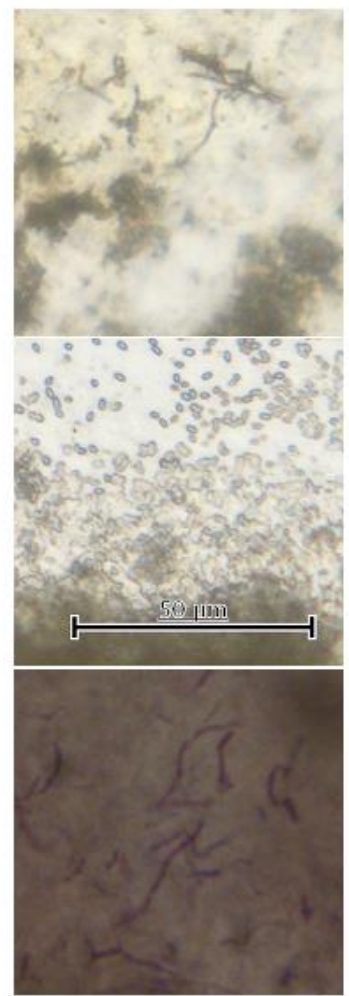

Figure 1. Images of macroscopic and microscopic evaluation of isolated actinomycetes. Microscopic observation was obtained using light microscopy at 400x magnification, except for T4P11, which was observed at 1000x magnification. (a) Y4K15, (b) Y3K21, (c) Y3K13, (d) Y4K23, (e) T3K24, (f) T3K11, (g) T4P11. 
Table 1. Summary of morphological and microscopic characteristics of isolated actinomycetes.

\begin{tabular}{l|l|l|c|c|c|c|l}
$\begin{array}{l}\text { Culture } \\
\text { Code }\end{array}$ & $\begin{array}{c}\text { Media } \\
\text { source }\end{array}$ & $\begin{array}{c}\text { Sample } \\
\text { source }\end{array}$ & $\begin{array}{c}\text { Aerial } \\
\text { mycelium color }\end{array}$ & $\begin{array}{c}\text { Vegetative } \\
\text { mycelium color }\end{array}$ & Spore color & $\begin{array}{c}\text { Sporulation } \\
\text { after 10 days }\end{array}$ & $\begin{array}{c}\text { Microscopic observation of } \\
\text { mycelium or spores }\end{array}$ \\
\hline Y4K15 & YECD & Wood & Maroon & Maroon & Grey & Good & Rectiaculiaperti \\
\hline Y3K21 & YECD & Wood & Colorless & Cream & Creamy-white & Good & Rectiaculiaperti \\
\hline Y3K13 & YECD & Wood & Colorless & Cream & Cream & Good & Rectiflexibiles \\
\hline Y4K23 & YECD & Wood & Colorless & Colorless & Creamy-white & Poor & Not observable \\
\hline T3K24 & TWYE & Wood & Pink-red & Colorless & White & Good & Rectiflexibiles \\
\hline T3K11 & TWYE & Wood & White & Cream & White & Good & Globose \\
\hline T4P11 & TWYE & Pith & Maroon & Maroon & Grey & Good & Rectiflexibiles
\end{tabular}

Fungal growth is rapid and expansive, making it difficult to obtain pure, uncontaminated actinomycete cultures. In this research, several attempts and reculturing had to be done to obtain a final pure actinomycete culture. Endophytic fungi are also a potential source of novel antibiotics [4]; thus, isolation of fungi using a medium optimized for fungal growth should be attempted from the same source.

Considering the status of Indonesia as one of the most biodiverse geographical regions in the world [21], actinomycetes isolation from Indonesian plants is currently under-utilized or undocumented. While the global number of actinomycetes is still undetermined, each plant species is found to have at least hundreds of endophytic actinomycetes species [14]. Indonesia is considered a hotspot with a large variety of plants [14]; however currently, there are only around 590 cultures currently collected in the Indonesian Culture Collection (InaCC) [29]. As stated earlier, the successful discovery of novel actinomycetes, and in turn, novel compounds, is achieved by exploring unique and difficult regions or sources [4]. As actinomycetes are also known to be endophytes, isolation of actinomycetes from plants is a potential source. However, it should be noted that differences in seasons, plant age, and other multiple environmental factors would influence the types of cultures obtained in an isolation project [30-33].

In this study, we report one culture of actinomycete found from the pith samples of the plants, encoded T4P11. However, we cannot cross the possibility that its true origins might have been from the inner wood surface; especially, considering that the morphological characteristics seem similar to another culture obtained from wood (Y4K15). A specific method to isolate actinomycetes or other endophytic samples from the pith of the plant should be developed, particularly considering that no other studies report actinomycetes nor fungal isolation from pith samples. Several research reports the effect of pathogenic bacteria that target plant pith [34,35]; therefore, it is probable that endophytic bacteria or fungi may exist in the pith of the plants, as shown in this study. Thus, further exploration studies targeting pith for the isolation of endophytic fungi and actinomycetes may be warranted.

\subsection{Antibiotic screening from isolated actinomycetes.}

Only two of the discovered actinomycetes showed any antibacterial activity. Antibiotic prodution from each culture against Staphylococcus aureus, Helicobacter pylori, and Escherichia coli (Figure 2). Against $S$. aureus, Y4K15 showed moderate antibacterial activity $(13.49 \pm 1.03 \mathrm{~mm})$, while Y3K21 and T4P11 showed weak antibacterial activity $(7.07 \pm 0.32 \mathrm{~mm}$ and $7.55 \pm 0.15 \mathrm{~mm}$, respectively). Similarly, these actinomycetes also showed activity against H. pylori, where again Y4K15 showed moderate activity $(14.9 \pm 0.7 \mathrm{~mm})$, and Y3K21 and T4P11 showed weak activity $(9.3 \pm 1.25 \mathrm{~mm}$ and $9.8 \pm 0.15 \mathrm{~mm}$, respectively). However, none of the actinomycetes showed any antibacterial activity against E. coli, despite both E. coli and H. pylori being Gram-negative bacteria. 


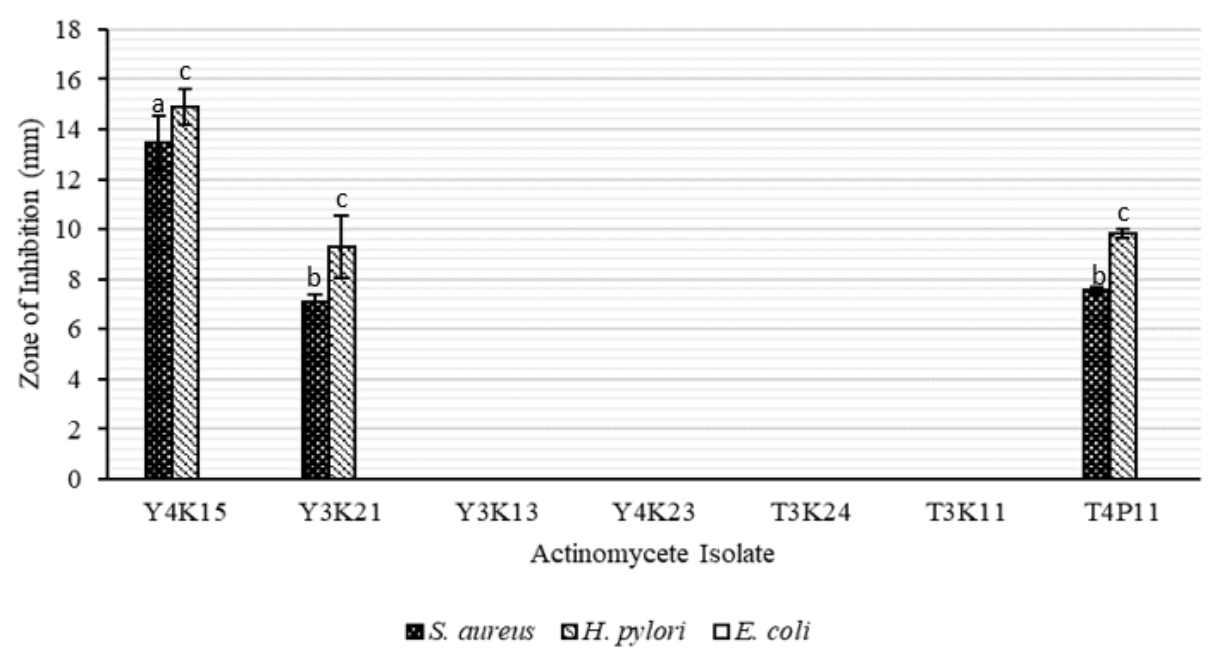

Figure 2. Antibiotic production against $S$. aureus, H. pylori, and E. coli after 14 days incubation in ISP2 medium. Y4K15, Y3K21, and T4P11 showed antibacterial activity against $S$. aureus and H. pylori, while other samples showed no antibacterial activity. Different letter annotation shows significant differences $(\mathrm{p}<0.05)$.

Three actinomycetes isolated in this study showed some antibacterial activity against $S$. aureus and $H$. pylori, but not $E$. coli, indicating the production of a narrow-spectrum antibacterial agent. Y4K15 was shown to have a moderate to strong activity against these two bacteria; however, the mechanism of action cannot be determined. While H. pylori and E. coli were both Gram-negative bacteria, some natural compounds have been shown to differentially affect these two bacteria even with their similarities [36-38]. On the contrary, some compounds are known to affect similarly against both $S$. aureus and $H$. pylori [37], despite their difference in cell wall type. Morphological and physiological differences and similarities between the tested bacteria are suspected to be a determining factor in antibiotic activity [39], which requires further studies in the isolation and identification of the bioactive compound.

Another factor to be considered in its mechanism of action is the possibility of more than one bioactive compound being produced. ISP2 medium has been known to be a good production medium in general [40-42]; however, the production of antibiotics from actinomycetes is influenced by many factors. Production of bioactive secondary metabolites is also preceded by sporulation [43-47], in which most of the actinomycetes had good sporulation formed at the time of harvesting and extraction. Aside from the metabolic and genomic capacity of each culture to produce bioactive compounds, certain studies have successfully induced bioactive compound production by adjusting the carbon and nitrogen source of the production medium, the inorganic compositions, or by adding certain trigger compounds to activate antibiotic production metabolic pathways [48-54]. However, these optimization studies are both time-consuming and expensive [55-56] and outside the scope of this paper.

Future directions for this research should include a genetic determination for Y4K15 and other species found in this study using 16S rRNA sequencing for species identification before conducting any optimization studies for antibiotic production and NMR identification of the bioactive compound itself. While laboratory findings do not always translate to clinical application, further characterization and optimization of the lead compounds discovered from Y4K15 may unearth novel antibiotic compounds with a different mode of action.

\section{Conclusions}

Isolation of actinomycetes from Tectona grandis (L.) wood and pith discovered seven actinomycetes with varying morphology, in which three had moderate to low activity against 
Staphylococcus aureus and Helicobacter pylori. This study highlights the potential of Indonesian plants in the discovery of endophytic actinomycetes species, particularly for the discovery of antibiotic compounds.

\section{Funding}

This study was supported by a research grant from Universitas Islam Malang, under the Hibah Institusi UNISMA (Hi-ma) program.

\section{Acknowledgments}

We would like to thank the committee in Lembaga Penelitian dan Pengabdian Masyarakat (LPPM), Universitas Islam Malang for the support. We would also like to thank Prof. Christopher M.M Franco from Flinders University for his consultation and support.

\section{Conflicts of Interest}

The authors declare no conflict of interest.

\section{References}

1. Marquardt, R.R.; Li, S. Antimicrobial resistance in livestock: advances and alternatives to antibiotics. Anim Front Rev Mag Anim Agric 2018, 8, 30-37, https://doi.org/10.1093/af/vfy001.

2. Castro-Vargas, R.E.; Herrera-Sánchez, M.P.; Rodríguez-Hernández, R.; Rondón-Barragán, I.S. Antibiotic resistance in Salmonella spp. isolated from poultry: A global overview. Vet world 2020, 13, 2070-2084, https://doi.org/10.14202/vetworld.2020.2070-2084.

3. Wang, C.-H.; Hsieh, Y.-H.; Powers, Z.M.; Kao, C.-Y. Defeating Antibiotic-Resistant Bacteria: Exploring Alternative Therapies for a Post-Antibiotic Era. Int $J$ Mol Sci 2020, 21, https://doi.org/10.3390/ijms21031061.

4. Hutchings, M.I.; Truman, A.W.; Wilkinson, B. Antibiotics: past, present and future. Curr Opin Microbiol 2019, 51, 72-80, https://doi.org/10.1016/j.mib.2019.10.008.

5. Katz, L.; Baltz, R.H. Natural product discovery: past, present, and future. J Ind Microbiol Biotechnol 2016, 43, 155-176, https://doi.org/10.1007/s10295-015-1723-5.

6. Newman, D.J.; Cragg, G.M. Natural Products As Sources of New Drugs over the 30 Years from 1981 to 2010. J Nat Prod 2012, 75, 311-335, https://doi.org/10.1021/np200906s.

7. Jakubiec-Krzesniak, K.; Rajnisz-Mateusiak, A.; Guspiel, A.; Ziemska, J.; Solecka, J. Secondary Metabolites of Actinomycetes and their Antibacterial, Antifungal and Antiviral Properties. Polish J Microbiol 2018, 67, 259-272, https://doi.org/10.21307/pjm-2018-048.

8. Law, J.W.-F.; Law, L.N.-S.; Letchumanan, V.; Tan, L.T.-H.; Wong, S.H.; Chan, K.-G.; Mutalib, N.S.A.; Lee, L.H. Anticancer Drug Discovery from Microbial Sources: The Unique Mangrove Streptomycetes. Molecules 2020, 25, https://doi.org/10.3390/molecules 25225365 .

9. Takahashi, Y.; Nakashima, T. Actinomycetes, an Inexhaustible Source of Naturally Occurring Antibiotics. Antibiot (Basel, Switzerland) 2018, 7, https://doi.org/10.3390/antibiotics7020045.

10. Culp, E.J.; Waglechner, N.; Wang, W.; Fiebig-Comyn, A.A.; Hsu, Y.-P.; Koteva, K.; Sychantha, D.; Coombes, B.K.; Van Nieuwenhze, M.S.; Brun, Y.V.; Wright, G.D. Evolution-guided discovery of antibiotics that inhibit peptidoglycan remodelling. Nature 2020, 578, 582-587, https://doi.org/10.1038/s41586-0201990-9.

11. Mohamed, H.; Miloud, B.; Zohra, F.; García-Arenzana, J.M.; Veloso, A.; Rodríguez-Couto, S. Isolation and Characterization of Actinobacteria from Algerian Sahara Soils with Antimicrobial Activities. Int J Mol Cell Med 2017, 6, 109-120, https://doi.org/10.22088/acadpub.BUMS.6.2.5.

12. Maiti, P.K.; Mandal, S. Lentzea indica sp. nov., a novel actinobacteria isolated from Indian Himalayan-soil. Antonie Van Leeuwenhoek 2020, 113, 1411-1423, https://doi.org/10.1007/s10482-020-01449-8.

13. Gacem, M.A.; Ould-El-Hadj-Khelil, A.; Boudjemaa, B.; Wink, J. Antimicrobial and Antioxidant Effects of a Forest Actinobacterium $\mathrm{V}(002)$ as New Producer of Spectinabilin, Undecylprodigiosin and Metacycloprodigiosin. Curr Microbiol 2020, 77, 2575-2583, https://doi.org/10.1007/s00284-020-02007-1.

14. Nalini, M.S.; Prakash, H.S. Diversity and bioprospecting of actinomycete endophytes from the medicinal plants. Lett Appl Microbiol 2017, 64, 261-270, https://doi.org/10.1111/lam.12718.

15. Li, K.; Guo, Y.; Wang, J.; Wang, Z.; Zhao, J.; Gao, J. Streptomyces aquilus sp. nov., a novel actinomycete isolated from a Chinese medicinal plant. Int J Syst Evol Microbiol 2020, 70, 1912-1917, 
https://doi.org/10.1099/ijsem.0.003995.

16. Zhao, H.; Yang, A.; Liu, J.; Bao, S.; Peng, R.; Hu, Y.; Yuan, T.; Hou, S.; Xie, T.; Zhang, Q.; Chen, X.; Wang, X.; Hu, L. Chartspiroton, a Tetracyclic Spiro-naphthoquinone Derivative from a Medicinal Plant Endophytic Streptomyces. Org Lett 2020, 22, 3739-3743, https://doi.org/10.1021/acs.orglett.0c00696.

17. Watanabe, Y.; Shinzato, N.; Fukatsu, T. Isolation of actinomycetes from termites' guts. Biosci Biotechnol Biochem 2003, 67, 1797-1801, https://doi.org/10.1271/bbb.67.1797.

18. Du, Y.E.; Byun, W.S.; Lee, S.B.; Hwang, S.; Shin, Y.-H.; Shin, B.; Jang, Y.-J.; Hong, S.; Shin, J.; Lee, S.K.; Oh, D.-C. Formicins, N-Acetylcysteamine-Bearing Indenone Thioesters from a Wood Ant-Associated Bacterium. Org Lett 2020, 22, 5337-5341, https://doi.org/10.1021/acs.orglett.0c01584.

19. Kaewkla, O.; Franco, C.M.M. Rational Approaches to Improving the Isolation of Endophytic Actinobacteria from Australian Native Trees. Microb Ecol 2013, 65, 384-393, https://doi.org/10.1007/s00248-012-0113-z.

20. Bhatti, A.A.; Haq, S.; Bhat, R.A. Actinomycetes benefaction role in soil and plant health. Microb Pathog 2017, 111, 458-467, https://doi.org/10.1016/j.micpath.2017.09.036.

21. Liang, J.; Crowther Thomas, W.; Picard, N.; Wiser, S.; Zhou, M.; Alberti, G.; Schulze, E.-D.; McGuire, A.D.; Bozzato, F.; Pretzsch, H.; de-Miguel, S.; Paquette, A.; Hérault, B.; Scherer-Lorenzen, M.; Barrett Christopher, B.; Glick Henry, B.; Hengeveld Geerten, M.; Nabuurs, G.-J.; Pfautsch, S.; Viana, H.; Vibrans Alexander, C.; Ammer, C.; Schall, P.; Verbyla, D.; Tchebakova, N.; Fischer, M.; Watson James, V.; Chen Han, Y.H.; Lei, X.; Schelhaas, M.-J.; Lu, H.; Gianelle, D.; Parfenova Elena, I.; Salas, C.; Lee, E.; Lee, B.; Kim Hyun, S.; Bruelheide, H.; Coomes David, A.; Piotto, D.; Sunderland, T.; Schmid, B.; Gourlet-Fleury, S.; Sonké, B.; Tavani, R.; Zhu, J.; Brandl, S.; Vayreda, J.; Kitahara, F.; Searle Eric, B.; Neldner Victor, J.; Ngugi Michael, R.; Baraloto, C.; Frizzera, L.; Bałazy, R.; Oleksyn, J.; Zawiła-Niedźwiecki, T.; Bouriaud, O.; Bussotti, F.; Finér, L.; Jaroszewicz, B.; Jucker, T.; Valladares, F.; Jagodzinski Andrzej, M.; Peri Pablo, L.; Gonmadje, C.; Marthy, W.; O’Brien, T.; Martin Emanuel, H.; Marshall Andrew, R.; Rovero, F.; Bitariho, R.; Niklaus Pascal, A.; Alvarez-Loayza, P.; Chamuya, N.; Valencia, R.; Mortier, F.; Wortel, V.; Engone-Obiang Nestor, L.; Ferreira Leandro, V.; Odeke David, E.; Vasquez Rodolfo, M.; Lewis Simon, L.; Reich Peter, B. Positive biodiversity-productivity relationship predominant in global forests. Science (80- ) 2016, 354, aaf8957-aaf8957, https://doi.org/10.1126/science.aaf8957.

22. Hajar, M.; Mohammed, I.; Siham, J.; Saad, I.; Abdellatif, H. Isolation, characterization and antimicrobial activity of a Streptomyces strain isolated from deteriorated wood. African J Microbiol Res 2014, 8, 11781186, https://doi.org/10.5897/ajmr2013.6444.

23. Coombs, J.T.; Franco, C.M.M. Isolation and identification of actinobacteria from surface-sterilized wheat roots. Appl Environ Microbiol 2003, 69, 5603-5608, https://doi.org/10.1128/AEM.69.9.5603-5608.2003.

24. Shirling, E.B.; Gottlieb, D. Methods for characterization of Streptomyces species. Int J Syst Evol Microbiol 1966, 16, 313-340.

25. Sibero, M.T.; Triningsih, D.W.; Radjasa, O.K.; Sabdono, A.; Trianto, A. Evaluation of Antimicrobial Activity and Identification of Yellow Pigmented Marine Sponge-Associated Fungi from Teluk Awur, Jepara, Central Java. Indones J Biotechnol 2017, 21, https://doi.org/10.22146/ijbiotech.26058.

26. Hudzicki, J. Kirby-Bauer Disk Diffusion Susceptibility Test Protocol Author Information. Am Soc Microbiol 2012, 1-13.

27. Huck, T.A.; Porter, N.; Bushell, M.E. Positive selection of antibiotic-producing soil isolates. J Gen Microbiol 1991, 137, 2321-2329, https://doi.org/10.1099/00221287-137-10-2321.

28. Gu, Q.; Liu, N.; Qiu, D.-H.; Liu, Z.-H.; Huang, Y. Isolation, classification and antimicrobial activity of endophytic actinomycetes from plant leaves. Wei Sheng Wu Xие Bao 2006, 46, 778-782.

29. InaCC. InaCC Online Catalogue. Indonesian Culture Collection (InaCC), Research Center for Biology, Indonesian Institute of Sciences (LIPI). http://inacc.biologi.lipi.go.id/index.php/Katalog/aktino. Published 2017.

30. Asraful Islam, S.M.; Math, R.K.; Kim, J.M.; Yun, M.G.; Cho, J.J.; Kim, E.J.; Lee, Y.H.; Yun, H.D. Effect of plant age on endophytic bacterial diversity of balloon flower (Platycodon grandiflorum) root and their antimicrobial activities. Curr Microbiol 2010, 61, 346-356, https://doi.org/10.1007/s00284-010-9618-1.

31. Alqahtani, A.; Tongkao-on, W.; Li, K.M.; Razmovski-Naumovski, V.; Chan, K.; Li, G.Q. Seasonal variation of triterpenes and phenolic compounds in australian Centella asiatica (L.) Urb. Phytochem Anal 2015, 26, 436-443, https://doi.org/10.1002/pca.2578.

32. Santos-Medellín, C.; Edwards, J.; Liechty, Z.; Nguyen, B.; Sundaresan, V. Drought Stress Results in a Compartment-Specific Restructuring of the Rice Root-Associated Microbiomes. MBio 2017, 8, https://doi.org/10.1128/mBio.00764-17.

33. Yang, S.S.; Tsai, S.H.; Fan, H.Y.; Yang, C.K.; Hung, W.L.; Cho, S.T. Seasonal variation of microbial ecology in hemlock soil of Tatachia Mountain, Taiwan. J Microbiol Immunol Infect 2006, 39, 195-205.

34. Catara, V. Pseudomonas corrugata: plant pathogen and/or biological resource? Mol Plant Pathol 2007, 8, 233-244, https://doi.org/10.1111/j.1364-3703.2007.00391.x.

35. Sutra, L.; Siverio, F.; Lopez, M.M.; Hunault, G.; Bollet, C.; Gardan, L. Taxonomy of Pseudomonas strains isolated from tomato pith necrosis: emended description of Pseudomonas corrugata and proposal of three unnamed fluorescent Pseudomonas genomospecies. Int J Syst Bacteriol 1997, 47, 1020-1033, https://doi.org/10.1099/00207713-47-4-1020.

36. Klesiewicz, K.; Karczewska, E.; Budak, A.; Marona, H.; Szkaradek, N. Anti-Helicobacter pylori activity of 
some newly synthesized derivatives of xanthone. $J$ Antibiot (Tokyo) 2016, 69, 825-834, https://doi.org/10.1038/ja.2016.36.

37. Sudjana, A.N.; D’Orazio, C.; Ryan, V.; Rasool, N.; Ng, J.; Islam, N.; Riley, T.V.; Hammer, K.A. Antimicrobial activity of commercial Olea europaea (olive) leaf extract. Int J Antimicrob Agents 2009, 33, 461-463, https://doi.org/10.1016/j.ijantimicag.2008.10.026.

38. Chen, M.-H.; Zhang, W.-L.; Chen, L.; Lin, R.; Xie, Y.; Fang, D.-S.; Lian, Y.-Y.; Jiang, H. Isolation, purification and identification of two new alkaloids metabolites from marine-derived Verrucosispora sp. FIM06025. Nat Prod Res 2019, 33, 2897-2903, https://doi.org/10.1080/14786419.2018.1509333.

39. Wang, L.; Huang, Y.; Yin, G.; Wang, J.; Wang, P.; Chen, Z.-Y.; Wang, T.; Ren, G. Antimicrobial activities of Asian ginseng, American ginseng, and notoginseng. Phytother Res 2020, 34, 1226-1236, https://doi.org/10.1002/ptr.6605.

40. Roy, S.; Halder, S.K.; Banerjee, D. Multi-Response Optimization of Granaticinic Acid Production by Endophytic Streptomyces thermoviolaceus NT1, Using Response Surface Methodology. Bioeng (Basel, Switzerland) 2016, 3, https://doi.org/10.3390/bioengineering3030019.

41. Elibol, M. Optimization of medium composition for actinorhodin production by Streptomyces coelicolor A3(2) with response surface methodology. Process Biochem 2004, 39, 1057-1062, https://doi.org/10.1016/S0032-9592(03)00232-2.

42. Tata, S.; Aouiche, A.; Bijani, C.; Bouras, N.; Pont, F.; Mathieu, F.; Sabaou, N. Mzabimycins A and B, novel intracellular angucycline antibiotics produced by Streptomyces sp. PAL114 in synthetic medium containing L-tryptophan. Saudi Pharm J SPJ Off Publ Saudi Pharm Soc 2019, 27, 907-913, https://doi.org/10.1016/j.jsps.2019.06.004.

43. Horinouchi, S. A microbial hormone, A-factor, as a master switch for morphological differentiation and secondary metabolism in Streptomyces griseus. Front Biosci 2002, 7, d2045-d2057, https://doi.org/10.2741/horinouc.

44. Kendrick, K.E.; Ensign, J.C. Sporulation of Streptomyces griseus in submerged Sporulation of Streptomyces griseus in Submerged Culture. J Bacteriol 1983, 155, 357-366.

45. Ueda, K.; Kawai, S.; Ogawa, H.; Kiyama, a; Kubota, T.; Kawanobe, H.; Beppu, T. Wide distribution of interspecific stimulatory events on antibiotic production and sporulation among Streptomyces species. $J$ Antibiot (Tokyo) 2000, 53, 979-982, https://doi.org/10.7164/antibiotics.53.979.

46. Yan, H.; Lu, X.; Sun, D.; Zhuang, S.; Chen, Q.; Chen, Z.; Li, J.; Wen, Y. BldD, a master developmental repressor, activates antibiotic production in two Streptomyces species. Mol Microbiol 2020, 113, 123-142, https://doi.org/10.1111/mmi.14405.

47. Vassallo, A.; Palazzotto, E.; Renzone, G.; Botta, L.; Faddetta, T.; Scaloni, A.; Puglia, A.M.; Gallo, G. The Streptomyces coelicolor Small ORF trpM Stimulates Growth and Morphological Development and Exerts Opposite Effects on Actinorhodin and Calcium-Dependent Antibiotic Production. Front Microbiol 2020, 11, 224, https://doi.org/10.3389/fmicb.2020.00224.

48. Cundliffe, E. Control of tylosin biosynthesis in Streptomyces fradiae. J Microbiol Biotechnol 2008, 18, 1485 1491.

49. Bibb, M.J. Understanding and manipulating antibiotic production in actinomycetes. Biochem Soc Trans 2013 , 41, 1355-1364, https://doi.org/10.1042/BST20130214.

50. Zhu, H.; Sandiford, S.K.; Van Wezel, G.P. Triggers and cues that activate antibiotic production by actinomycetes. J Ind Microbiol Biotechnol 2014, 41, 371-386, https://doi.org/10.1007/s10295-013-1309-z.

51. Olano, C.; Lombó, F.; Méndez, C.; Salas, J.A. Improving production of bioactive secondary metabolites in actinomycetes by metabolic engineering. Metab Eng 2008, 10, 281-292, https://doi.org/10.1016/j.ymben.2008.07.001.

52. Thakur, D.; Bora, T.C.; Bordoloi, G.N.; Mazumdar, S. Influence of nutrition and culturing conditions for optimum growth and antimicrobial metabolite production by Streptomyces sp. 201. J Mycol Med 2009, 19, 161-167, https://doi.org/10.1016/j.mycmed.2009.04.001

53. Xia, H.; Zhan, X.; Mao, X.-M.; Li, Y.-Q. The regulatory cascades of antibiotic production in Streptomyces. World J Microbiol Biotechnol 2020, 36, https://doi.org/10.1007/s11274-019-2789-4.

54. Barreales, E.G.; Payero, T.D.; Jambrina, E.; Aparicio, J.F. The Streptomyces filipinensis GammaButyrolactone System Reveals Novel Clues for Understanding the Control of Secondary Metabolism. Appl Environ Microbiol 2020, 86, https://doi.org/10.1128/AEM.00443-20.

55. Robertsen, H.L.; Weber, T.; Kim, H.U.; Lee, S.Y. Toward Systems Metabolic Engineering of Streptomycetes for Secondary Metabolites Production. Biotechnol J 2018, 13, https://doi.org/10.1002/biot.201700465.

56. Amiri, S.; Mokarram, R.R.; Khiabani, M.S.; Bari, M.R.; Alizadeh, M., Optimization of food-grade medium for co-production of bioactive substances by Lactobacillus acidophilus LA-5 for explaining pharmabiotic mechanisms of probiotic. J. Food Sci. Technol. 2021. 58, 1-12, https://doi.org/10.1007/s13197-020-04894-5. 